\title{
Ideophones and the nature of the adjective word class in Ewe ${ }^{*}$
}

\author{
Felix K. Ameka \\ Max Planck Institute for Psycholinguistics \\ and Leiden University
}

\section{Introduction}

In his overview of African ideophones, Childs (1994:197) notes that one of the issues that remains "[Still] to be scrutinized is the exact nature of the relationship between ideophones and the rest of the language, as well as the place of ideophones in a language." The present paper seeks to contribute to this topic of research by examining the consequences the place given to ideophones in a language description has for typological generalizations about that language. I argue that one cam arrive at different generalizations about the nature of the adjective word class in a language depending on the place of ideophones in the language. I illustrate the point with data from Ewe, a Kwa language of West Africa. I explore the implications of ignoring ideophones for our understanding of the structuring of conceptual domains such as color in the language. Furthermore, I argue that contrary to being peripheral elements, ideophones form an integral part of the languages in which they occur and they should therefore not be ignored, but should be considered in their typological characterizations.

Research on ideophones is beset with problems of finding a cross-linguistically valid definition for the term 'ideophone' and its progress has been hampered by emphasizing the peripheral and the irregular nature of ideophones. A way forward, it seems to me, is to attempt to discover correlations between the properties that have been documented for ideophones in specific languages and the linguistic type of these languages. In other words, it appears that some of the properties of ideophones that have been noted in the literature apply only to certain language types and others to languages of other types. To give a rather trivial example, a morphological property that has been noted for ideophones in description after description is that "ideophones display very little morphology" (Childs 1994: 185). 
Sometimes ideophones are said to be uninflected words (cf. Schultze-Berndt this volume). However, such statements are only applicable to languages that are of a certain morphological type, namely the inflecting ones. Such a feature is irrelevant for an isolating language (with agglutinative features) such as Ewe. I suspect that many of the features that have been noted for ideophones co-vary in similar ways with the typological properties of the languages in which they occur.

I assume that ideophones are a phonosemantic class of words with expressive and imaginistic semantics (cf. Kita 1997). They are first and foremost a type of words - a lexical class of words - which need not belong to the same grammatical word class in a particular language nor across languages (cf., e.g., Newman 1968). In this sense they are like deictic words with a particular semantic function but which can fall into different grammatical word classes - nominal, adverb, verb, or adjective etc. - in a particular language.

The question of the nature of the relation between ideophones and the rest of the language arises because they have been marginalized and treated as extrasystematic mysterious words (cf. Newman this volume; Matisoff 1994). Ideophones have been defined and assumed to be peripheral to language because they tend to have peculiar structural linguistic properties. It is the contention in this paper, however, that we cannot understand the nature of the relation of ideophones to the rest of the language if we do not take seriously the observation made by a number of people that languages differ in the extent to which ideophones are integrated into the grammar (Moshi 1993; Childs 1994; Dumestre 1998; McGregor this volume; among others). As Childs (1994: 188) put it: "Ideophones can be variably assimilated into a language and this fact determines their diffusion into other word classes or their isolation in their own word class". It seems that different salient properties of ideophones that have been identified in the literature correlate with whether all ideophones in a language belong to one syntactic class or they are distributed over a number of syntactic classes in the language.

A cursory survey of descriptions shows that languages where ideophones are said to be grouped in a word class or are a subclass of one word class only are those in which individual ideophones tend to collocate exclusively with specific words. They tend to be syntactically independent in a clause and carry special sentence stress or intonation patterns and are used only in affirmative declarative utterances. This seems to be the case in some Bantu languages such as KiVunjo-Chaga (Moshi 1993) and also in Fulfulde (Breedveld 1995). At the other end of the continuum are languages in which ideophones are found in many more classes and they tend not to have any special intonation, individual ideophones have wider distribution both in terms of co-occurrence with other words and in terms of the utterance types in which they occur. Kwa languages like Dangme (Dakubu 1998) and Ewe seem to occupy this end of the scale. In Ewe, as we shall see below, ideophones are found in several word classes, and are used in declaratives, questions, imperatives and also in 
negative sentences. Languages can be plotted in between these two points. Bambara provides a nice illustration of this gradation. Dumestre (1998) indicates that Bambara ideophones generally belong to a class of expressive adverbs. As members of this adverb class they occur only in affirmative sentences; they tend to occur sentence finally, and are produced on a high pitch. However, when they function as noun or verb they lose the special high pitch and can occur in negative sentences as well (Dumestre 1998:331).

Another parameter for distinguishing among languages in which ideophones are found is whether in a particular language ideophones are introduced in an utterance by a demonstrational quotative verb or form. In the first place distinctions can be made with respect to the number of such forms that are used in a particular language. Secondly, a correlation can be made with respect to whether the ideophones belong to one class or several classes in the particular language. For instance, in Zulu where ideophones reportedly constitute a class of their own the form thi 'do' is used to introduce ideophones (Childs 1994; Poulos and Msimang, this volume). ${ }^{1}$ However, Quechua in which ideophones also presumably fall into one class does not have any such introducing demonstrational lexical item (Nuckolls 1996). Similar differences occur in languages where ideophones fall into more than one class. In Kana, a Kegboid language of Nigeria, which has ideophonic adjectives, ideophonic nouns and ideophonic adverbs, the ideophonic adverbs have to be introduced by a form dod 'do, like'. The same form is used to verbalize some of the nominal ideophones (Ikoro 1996:296-301). In Ewe, by contrast, the adverbial ideophones are used in a clause like any other adverb without any such demonstrational quotative form, and ideophonic words can be complements to the verb wo 'do, make' just like non-ideophonic nouns and adverbs can. I should add that the collocation of ideophones with the verb wa 'do, make' is linked to the use of the verb to predicate qualities of other entities (Westermann 1930:93; Ameka 1994:71). In this usage, any nominal or adverbial word that has a quality component in its meaning can function as the complement to give a predicative quality interpretation. Consider the following example. ${ }^{2}$

(1) E-wo tsi / túkúi-dé /legbee

3sG-do water small-ADV long

noun adverb ideophonic adverb

'It is watery/small/long.'

Similar correlations can be attempted for the distribution of ideophones across discourse genres or types. It is usually claimed that ideophones are only used in narrative genres or rather that they tend to be restricted to narrative genres. For example, Schaefer (this volume) notes that ideophonic manner adverbs are not used in conversation in Emai (Benue-Congo, Nigeria). However, Tassa (this volume) observes that ideophones occur frequently in Tetela (Bantu, Democratic Republic 
of Congo) conversation. The same can be said for Ewe where ideophones occur in different kinds of interactional discourse including telephone conversations. Here is an excerpt from a recent telephone conversation involving the author (FA) and another speaker (FT). The excerpt is taken from the "how are you enquiry" segment of the interaction. It is significant, I think, that ideophones can be introduced into routine exchanges of this kind.

(2) FA: Alékề

'How (is it)?'

FT: Me-le dzi buta buta buta

1 SG-be:PRES upper-surface IDEO IDEO IDEO

'I am on it and it changes by leaps and bounds.'

Does this distribution have anything to do with the degree of integration of ideophones in the grammar of a language?

The rest of the paper is concerned with how the way ideophones are viewed can affect typological generalizations with respect to the adjective word class. In Section 2, I pose the problem that ideophones present to the characterization of the adjective word class in African languages. Section 3 is a description of the salient properties of ideophones in Ewe. This is followed in Section 4 by a scrutiny of the nature of the adjective class in Ewe in relation to ideophones and from a crosslinguistic typological perspective. Section 5 considers some of the consequences for excluding ideophones from consideration for the description of the conceptual domain of color. The paper ends in Section 6 with some concluding remarks.

\section{A paradox}

References abound in the literature concerning the fact that many African languages have a closed class of underived adjectives (e.g. Welmers 1973). Many of the studies upon which such claims are based tend not to consider ideophones. For instance, Madugu (1979) argues that adjectives have merged with verbs in Yoruba and that the adjective class is a small closed one. He concedes that "Although it is conceivable that ideophonic expressions, particularly those employed to describe physical objects (e.g. roboto 'round') are an important source of adjectives in the language, ideophones are not considered in this study" (Madugu 1979:85-86). Welmers and Welmers (1969) also claim that there are only eight adjectives in Igbo with no due regard to ideophones. Bot Ba Njock's (1977:207) rhetorical question: "y-a-t-il des adjectifs qualificatifs dans votre langue?" also assumes that adjectives are rare in African languages.

One may well wonder if these claims would be maintained if ideophones or rather ideophonic adjectives were taken into account. This becomes especially 
pertinent in the context of the other widespread view that many African languages have ideophones which are a set of "descriptive or qualificative words" (Newman 1968: 107). This means that at least some ideophones code qualities. And if adjectives code qualities or property concepts then it would seem to me that ideophones have to be considered in the description of the adjective class in these languages. Furthermore, since it is generally agreed that ideophones are an open and productive lexical class in the languages in which they occur (cf. e.g. Childs 1994) then one suspects that languages that have ideophonic adjectives cannot be said to have a closed class of adjectives. In fact those who take an evolutionary view of the way ideophones get integrated in the grammar argue that ideophones are a source of adjectives in some languages. For instance, Moshi (1993) thinks that when ideophones start out from a class of their own "in time some ideophones ... become grammaticalized like adjectives and adverbs and acquire a refined or attenuated lexical meaning" (Moshi 1993: 190). Similarly, Westermann (1930:189) asserted long ago with respect to Ewe that "It is unquestionable that many words (substantives, verbs, adjectives) have their derivation in these picture words [i.e. ideophones]". Implicit in these statements is the assumption that once ideophones have become grammaticalized they lose ideophonic status. But this need not be the case. Rather, the ideophonic words augment the class into which they are integrated. In addition this does not necessarily involve derivation on a synchronic level. Hence such forms cannot be thought of as derived elements. Besides, given the tendency for ideophonic words not to participate in overt morphological processes and the tendency for ideophones to have multiple categorization in some languages, it is hard to talk of the form in one category as being derived from the other. This is more so the case in a language like Ewe where word classes are defined on the basis of syntactic distributional properties of word forms.

Moreover, this is not inconsistent with a perspective on the adjective class as an emerging class, at least in some West African languages (Ameka 1986, 1991; Schaefer and Egbokhare 1993; and cf. Lindsey and Scancarrelli 1985 on Cherokee). Schaefer and Egbokhare (1993:174) suggest that "the Emai property concept system is undergoing a change" in which at an earlier stage "verbs were the dominant, and perhaps only, means for coding property concepts. The presence of adjectives and nouns in the present system is thus an innovation."

It should be evident then that one cannot ignore ideophones in the discussion of adjective classes in the languages in which they occur. Yet this is what the practice has been in many studies. I will show in Section 4 that different conclusions are arrived at about the nature of the adjective class in Ewe depending on whether ideophones are included in the discussion or excluded from it. Before turning to this, I present an overview of Ewe ideophones in the next section. 


\section{Properties of Ewe ideophones}

Westermann (1930:187) draws attention to the fact that a large part of the Ewe lexicon is made up of ideophones which he called "picture words" He writes:

The language is extremely rich in means of translating an impression into sound. This wealth arises from an almost irrepressible desire to mimic and to describe by one or more sounds everything heard or seen, or any impression however received. These expressions we call picture words.

These ideophonic words can be identified on the basis of phonological, morphosyntactic and semantic properties (see e.g. Westermann 1927, 1930, 1937; Ansre 1966; Geraldo 1980; Awuku 1992; Duthie 1996).

Phonologically, some ideophonic words contain non-canonical CVV or CVN syllable structure. For example, kpó́ 'quietly'; glomos 'crooked, uneven'; kén 'completely'; kpam 'sound of a collision between surfaces'. Similarly, some of them have syllabic ' $r$ ' as in words like prrrr 'sound of a whistle' and gbrrr 'sound of thunder'. Furthermore, the phonotactic constraint in the language where $[r]$ does not occur after grave sounds is violated in some ideophones as prrrr 'sound of a whistle' and gbrrr 'sound of thunder' illustrate. The deviations from the canonical phonological patterns noted here are not exclusive to ideophones. Some loanwords and non-ideophonic interjections exhibit such properties too (cf. Ameka 1992).

Other phonological properties typical of ideophones include the use of phonation types, such as breathy voice or growl, in the production of some ideophones which are not otherwise used in the main sound system. Similarly, word final vowel lengthening is used for expressive purposes in ideophones but rarely, if ever, in non-ideophonic words. For instance, the words fü $\bar{u}$ 'a lot' and lotoo 'big and round' can have their final vowels lengthened for intensity as in fũ $\tilde{u} \tilde{u} \tilde{u} \tilde{u} . .$. 'pleee...nty' and lotoooo... 'very big and round'.

The tonal register of ideophonic words can also be varied to symbolize different kinds of meaning. Thus a bad smell can be simply described with the word kũu 'bad smell' with regular low tone. The same word can however be produced on an extra low register to indicate that the smell is a very bad one. Furthermore, High and non High tones may be varied on the same sequence of segments to symbolize different values of various properties. High tone or register is symbolic of nice, pleasant, sweet, good and small. Low tone or register is used to indicate bad, unpleasant, sour and big dimension. Compare the following pairs of words:

(3) Iílílfílí ...

'nice good sweet smell'

pótópótó

'sound of a small drum' litiliti ...

'very bad smell'

potopoto

'sound of a big drum' 
The syllables of some disyllabic ideophones can be permuted. The semantic nuances between the two variants in most cases are so subtle that they are hard to capture. Consider the following pairs:

\begin{tabular}{|c|c|c|}
\hline tsaklii & klitsaa & 'rough surface' \\
\hline dzahlii & hlidzaa & 'tough and plumpy' \\
\hline kolii & likıo & 'black and thick smoke' \\
\hline nyadrii & drinyaa & 'tough' \\
\hline kpodzos & dzokpos & 'thick and round' \\
\hline nogoo & gonoo & 'round' \\
\hline
\end{tabular}

In other cases, however, such permutations can lead to wider semantic differences. For example,

(5) bbos 'long'
bolos

It is not immediately obvious how this process should be accounted for. Ann Senghas (p.c.) suggests that it might be the result of reduplication followed by truncation. On this view a form like tsaklii is reduplicated to form tsaklitsaklii and then there is the deletion of the first and the last syllables yielding klitsa. Then final vowel lengthening has to take place after the truncation to make the form fit the template. This is a very plausible scenario given the fact that the reduplicated form is a well formed ideophonic word. It is also consistent with Steriade's (1988) formal account of reduplication. For Steriade, reduplication begins with total reduplication of the base followed by pruning of the reduplicated material to meet the wellformedness conditions on the template. The formal as well as the semantic properties of these ideophonic constructions require further investigation. For instance, ideophonic forms comparable to those in the first column in (4) do not undergo this process (see 6).

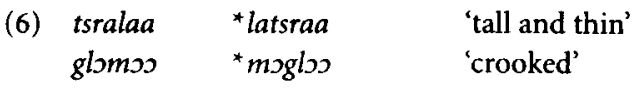

It is thus not clear what the formal restrictions on the input to the process are. Suffice it to say that, non-ideophonic words do not undergo such permutation of their internal structure.

Few ideophonic words in the language have an inherently repetitive structure with no corresponding monosyllabic form. Thus there is no form * nya which could be the base of the triplicated form used in the following example (7). Note, however, that the repetitive structure is in most cases iconic with the semantics of the form.

(7) dolá-wó fú du kplé dzodzo nyanyaanya servant-PL MOVE course with RED-jump trembling-IDEo ' $\ldots$ the servants run with much trepidation trembling.' 
Typically, ideophones undergo syntactic iteration (i.e. word repetition) rather than morphophonological reduplication or triplication (see Ameka 1999)

(8) gbo dzi blewu blewuи

breathe heart IDEO IDEO

'Be patient in a calm and soft way.'

There is no grammatical word class of ideophones as such in Ewe. Ideophonic words can fall into any syntactic class of the language. Thus there are nominal, adjectival, intensifier, verbal, adverbial as well as interjection ideophonic words. Many ideophonic words have multiple categorization and their conversion from one class to the other, so to speak, is by zero derivation (see below on verb-adjective-adverb forms). Thus an ideophone like atuu 'embrace' can function either as an interjection or an adverb (Ameka 1992). Similarly, some words such as fútú 'plenty' and kén 'completely' function either as Intensifiers (in the NP) or as adverbs (Ansre 1988; Duthie 1996). Some ideophones function only as adverbs, for example, fío; or fíofíofíofió 'completely', hoyihóyihóyi 'bitter sharp taste'. Ideophonic

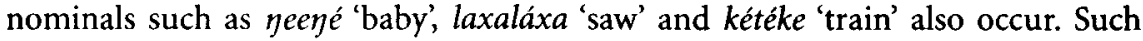
ideophonic nominals function just like any other nominal in the language. In example (9a) below the ideophonic nominal occurs preposed to the verb in an imperfective aspect construction. This is one of the tests of argumenthood of verb complements (see Essegbey 1999 for justification of this test). However, in example (9b) the form gbudugbudu functions as an adverb and occurs after the temporal noun which cannot function as an argument.
a. Wó-le gbùdùgbùdù wo-ḿm
3PL-be-PRES IDEO do-PROG
'They are causing tumult.'
b. Wb-no avu wo-m ets go gbùdùgbùdù
3.PL-be.N.PRES fight do-PROG yesterday IDEo
'They were fighting yesterday in a tumultuous way.'

As noted earlier, ideophonic words in Ewe are used in all sentence types in the language as illustrated in (10).

(10) a. Mi-zo minyaminya ...

(IMPERATIVE)

2PL-walk IDEO

'Walk stealthily ...' (a line from a dirge)

b. Mi-ga-wo gbùdùgbùdù $o$

(PROHIBITIVE)

2PL-REP-dO IDEO

NEG

'Do not engage in tumultuous behavior.'

c. ... mé-wo-a ba fanyafanya o.

(NEgATIVE)

3.SG.NEG-do mud IDEO NEG

'... it does not become very clumsily muddy' (Nyaku 1958:11) 

d. E-nya-e
wò-fu
tittitititi-a?
(QUESTION)
2.sG-wash-3.sG 3.sG-become white IDEO-Q
'Have you washed it immaculate white?'

Ideophones can be used quotatively as if they were representing a sentence in context as in (11a). The ideophone could also be embedded in a quotative clause and introduced by the complementizer bé 'that' as in (11b). Furthermore, in contexts where the ideophones are used demonstrationally, they can be embedded as complements to the nominal demonstrational word alé 'like this'. In this case the ideophones do not behave differently from other gestures or demonstrations which depict the form of what is being talked about.

(11) a. E-fú así nu bóbóbó
3sG-strike hand mouth IDEO
'S/He raised an alarm and went "bóbóbó".'
b. E-fú asi nu bé bóbóbó
3SG-strike hand mouth comP IDEO
'S/He raised an alarm and went "bóbóbó".
c. Tsi lá fá (á)lé míamíamímiámía
water DEF be-cold like-this IDEo
'The water is very pleasantly cold and soothing.'

As noted earlier, ideophones are used in Ewe in different kinds of discourse conversational including telephone conversations, radio and television broadcasts and narrative etc. The functions of ideophones in the different types of discourse deserve more systematic study. Initial ideas on the functions of ideophones in Ewe narrative discourse are presented in Konrad (1994). She comments on the use of ideophones in the performance of folk tales as follows:

... ideophones are ... literary devices used to heighten dramatic tension, to accentuate certain actions and to draw attention to certain images and deemphasize others.... Ideophones are in effect an enormously affective and efficient tool performers have at their disposal to develop the privileged relationship shared between narrator and audience in a culturally defined context. (Konrad 1994: 108)

Konrad found that in one of the tales in her corpus eleven different ideophones were used. A cursory glance through the texts recorded in the book shows that ideophones occur in each of them. Thus Ewe ideophones are indeed used in narratives but they are not restricted to such genres alone.

\section{What is the nature of the adjective class in Ewe?}

Although Ewe grammarians agree that there is an adjective class in the language, 
there are differing views on the constitution of the class. Before examining these views, let us consider what it means to say that a language has 'a class of adjectives'? According to Lyons (1977:440-1)

When we say that there are adjectives $[\ldots]$ in such and such a language, we mean that there is a grammatically definable class of expressions whose most characteristic syntactic function is that of being the modifier of the noun in an endocentric construction and whose most characteristic semantic function is to ascribe properties to entities. It does not follow [...] that all (or indeed any) of the adjectives [...] will be lexemes; it is in principle possible that some (or indeed) all of these should be formed by productive grammatical processes belonging to other parts-of-speech.

Dixon (1982:56), on the other hand, asserts that an adjective class "is a set of lexical items distinguished on morphological and syntactic grounds from the universal classes of Noun and Verb [.... Semantically, an adjective describes some important but non-criterial property of an object" [emphasis added F.A.] In fact, in Dixon's analysis he makes a distinction between 'deep' or 'basic' adjectives, i.e. lexical items defined by the above criteria, and 'surface' adjectives, i.e. words that function as adjectives but are derived from other word classes. In making decisions about the nature of the adjective class of a language, Dixon only considers the size of the 'deep' or underived adjectives.

Different findings will be made in respect of the adjective class in a language depending on whether one follows Dixon's or Lyons' definition. Essentially, by following Dixon the only items that one will consider as adjectives are roots whereas by following Lyons one will consider both roots and derived items.

Different positions have been taken on the nature of the adjective class in Ewe, which reflect these views. Westermann (1930:183) suggests that all the members of the adjective class in Ewe, if there is one, are derived from other classes. In his words

There are no words which are adjectives pure and simple. All expressions which serve as adjectives are either (1) also substantives or formed from substantives or (2) actually verbs or formed from verbs or (3) combinations of verbs and substantives or (4) also adverbs or (5) picture words [i.e. ideophones F.A.]

Evidently, Westermann thinks that there are no adjectival roots in the language and that all forms that could behave syntactically and semantically as adjectives on occasion were either derived or belonged to another word class. If one were to interpret Westermann's claim in terms of Dixon's definition one would have to conclude that Ewe does not have a class of adjectives. On the other hand, if one were to apply Lyons' views then one would have to conclude that Ewe has an adjective class, even if according to Westermann they are all derived. Significantly 
for our present purposes, Westermann acknowledges that ideophones belong to the adjective class. He assumes however, that there is a class of ideophones which form a subclass of adverbs in the language. ${ }^{3}$ In my view, there are ideophonic adjectives as well as ideophonic adverbs and the one need not be derived from the other.

Ansre (1966:213) presents another view and rightly points out, albeit in a footnote that: "The assertion by Westermann that 'there are no words which are adjectives pure and simple' is inaccurate and must be attributed mainly to lack of sophistication in tonal analysis and too great a tendency to etymologize." Ansre sets up two structural classes of adjectives: the simple - monomorphemic, presumably, the underived adjectives - and the non-simple, the polymorphemic, or the derived forms. He does not make any statements about the size of these sub-classes. Nor does he say anything about the possibility for some of the simple adjectives to have multiple categorization. Interestingly, two of the three simple adjectives that Ansre (ibid.) cites are ideophonic words which can also function without any additional material as verbs or adverbs. (see example [15] below). This means that Ansre considers ideophonic adjectives as underived forms contra Westermann.

Primarily, the adjective class in Ewe has to be defined in terms of distributional properties. An adjective in Ewe can be described as an item that immediately follows the noun head and precedes other modifiers if there are any in an endocentric NP. It serves to describe a property of the noun. The order of elements in a simple noun phrase is:

identifier noun adj quantifier DETl-DET2/DEM plural intensifier

Example (12) below is a simple NP in which all the slots have been filled. Notice that there are three adjectives in this example. In (13) further examples of NPs are given with different types of modifiers together with adjectives.

(12) neném nysnu kskś tralaa dzetugbe

such woman tall slender beautiful

QT DEM PL INT INT

eve má- wó kón ko

two that PL just only

'only those same two tall slender and beautiful women'

(13)
a. awu yi/yé lá
garment white DEF
'the white garment'
b. to gáa, goglỏ má
river big deep DEM
'that big deep river'

The above examples contain different features of adjectives in Ewe. Adjectives can occur in sequence in one NP. In (12) the three adjectives belong to different 
subclasses: $k \delta k s$ 'tall' is derived from the verb $k s$ 'be(come) tall'. On the other hand, dzetugbe 'beautiful' is derived by the compounding of a verb dze 'make contact' and the property denoting noun tugbe 'beauty'. Unlike these two, tralaa 'slender, tallthin' is a simple underived ideophonic adjective. The forms gá 'big' and yi/yé 'white' which occur in (13) are also simple adjectives but they are non-ideophonic. While the form goglo 'deep' in (13b) looks like a derived form because of its reduplicated nature, there is no synchronic verbal base * $g l o$ for it. Such forms are diachronic derivations which have become lexicalized (see Ameka 1991). The elements that fill the adjective slot may thus be simple or underived, derived transparently or diachronically derived forms. The adjectival forms are used only attributively. The predicative function of the attributive adjectives is performed by verbs, nouns or adverbs. The sentences in (14) below illustrate the morphosyntactic expression of the property concept 'big' both attributively and predicatively.

$$
\begin{aligned}
& \text { a. Máwú gắ } \\
& \text { God big } \\
& \text { 'Supreme God' } \\
& \text { b. Máwú nyé gă } \\
& \text { God cop big } \\
& \text { 'God is (the) big/great (one)' } \\
& \text { c. E-le gáa dé } \\
& \text { 3sG-be-at.pREs big-ADV } \\
& \text { 'S/He /it is big' }
\end{aligned}
$$

(ADJECTIVE, attributive)

(predicate NOMINAL)

(ADVERB, predicative)

The verb lolo 'be large, big' that is synonymous with gâa 'big' can be used as its verbal counterpart in predicative function as in (13d).

(14) d. Máwú lolo

God be-large

'God is great'

In the rest of the paper we will be concerned with the class of underived adjectives mainly because this is the class whose existence crosslinguistically and in African languages has been in doubt. As noted earlier, two subclasses of underived monomorphemic adjectives can be distinguished in Ewe. The classification is based on the ability of an item to convert to other classes by overt morphological means or by zero derivation (cf. Duthie 1996:57). This corresponds, by and large, to whether they are ideophones or not. In examples $(14 \mathrm{a}-c)$ we saw that the simple adjective gá 'big' converted to other categories namely, noun and adverb, by overt morphological means. Compare the forms of tralaa 'slender, tall-thin' in (15) to the forms of the property concept words in (14) as well as (16).

(15) a. [ útsu lá $]_{N P}[\text { tralaa }]_{\mathrm{VP}}$.

man DEF thin-tall

'The man is tall and thin ?lanky.' 
b. [yútsu tralaa $\left.l a]_{\mathrm{NP}} v a\right]_{\mathrm{VP}}$. man thin-tall DEF come

'The tall and thin (?lanky) man came.'

c. $\quad[\text { uutsu lá }]_{\mathrm{NP}}[k \zeta]_{\mathrm{VP}}[\text { tralaa }]_{\mathrm{AP}}$.

man DEF be-tall thin-tall

'The man is tall in a tallish-thinly (lanky) manner.'

(16) a. [deví lá $]_{\mathrm{NP}}[\text { nyó }]_{\mathrm{VP}}$ child DEF be-good

'The child is good.'

b. [deví nyúí lá $]_{\mathrm{Np}}[x o]_{\mathrm{VP}}[\text { fetú }]_{\mathrm{NP}}$. child good DeF get pay

'The good child got a prize.'

c. [devi lá $]_{\mathrm{NP}}[\text { háyá }]_{\mathrm{VP}}[\text { nyui-él nyoe-dé }]_{\mathrm{AP}}$ child DEF recover good-ADV good-ADV

'The child recovered well.'

The word tralaa in example (15) is one of Ansre's simple adjectives. It can be seen from the example that in addition to functioning as an adjective in (15b) it can also function as a verb as in (15a) and as an adverb as in (15c) without any change in form. Some support for this can be found from a comparison of the forms with those in (14) and (16). In (16b) nyui 'good' is an adjective and it is derived from the verb nyó 'be good' which occurs in (16a). The adverbial form nyuie (or nyoedé) 'well' in (16c) is derived from the adjective form by the suffixation of $-e$ or $-d \dot{e}$ 'adverbializing suffix' depending on one's dialect. In this case the difference in grammatical function is overtly marked. Thus the form gấ 'big' in (14a) and tralaa in (15b) are both simple adjectives but they each belong to the two different subclasses. The former to the class of those underived adjectives that convert to other categories by overt morphological means and the latter to the class of those underived adjectives that convert to other categories by zero conversion. The two subclasses correspond largely to a difference between the non-ideophonic (overt conversion) and ideophonic (zero conversion) adjectives.

A useful framework for talking about the nature and typological patterning of adjectives is provided by Dixon (1982, 1994) (see also Madugu (1979), Thompson (1988), Schaefer and Egbokhare (1993)). The discussion of the features of simple adjectives in Ewe will be cast in this framework after its relevant tenets are described.

\subsection{Dixon's semantic types for adjectives}

Dixon distinguishes three levels of description; a universal semantic level, a basic or 'deep' level and a surface level. At the universal semantic LeVEl concepts represented by dictionary items in a language are grouped into 'semantic types' 
belong to the verb class and HUMAN PROPENSITy tends to go with the noun class and SPEED is grouped with adverbs. Dixon's examples of such languages include Hausa, Igbo and Hua.

The second dimension has to do with whether the language is verb dominated or adjective dominated. STRONGLY ADJECTIVAL languages such as Dyirbal are those in which the seven types are exclusively associated with a single part-of-speech, the adjective class. In such a language, the polar opposites all belong to the same class. In STRONGLY VERBAL languages the marked pole of many adjectival oppositions are realized by a verb (cf. raw vs. cooked, whole vs. broken or by a noun. Hausa and Alamblak are examples of such languages. NEUTRAL languages have both poles of most oppositions expressed by adjectives but for a few which involve a state resulting from an action the marked pole may be realized by a verb. English is the clearest representative of this with respect to pairs such as raw and cooked.

Dixon's findings are based on the deep or basic level which is not without problems (see Ameka 1991:100-102 for a discussion). However, it is a useful heuristic for talking about property concepts and their class membership in general and for examining ideophonic words that code properties from that point of view.

\subsection{Semantic classes of Ewe simple adjectives}

\subsubsection{Non-ideophonic simple adjectives}

There are five non-ideophonic adjectival monomorphemic items which have to be overtly marked for conversion to other categories, for example, adverbs.

\begin{tabular}{|c|c|c|c|c|}
\hline$g \hat{a}$ & 'big', & $v i$ & 'small' & (DIMENSION) \\
\hline vร́ & 'bad', & & & (VALUE) \\
\hline$y^{i} / \gamma^{e ́}$ & 'white' & $d z \bar{i} / d z \bar{e}$ & 'red' & (COLOR) \\
\hline
\end{tabular}

If one does not consider ideophonic adjectives then one can conclude that Ewe has a closed class of five adjectives. ${ }^{4}$ Note that they fall within the semantic types that Dixon predicts. In fact the behavior of the non-ideophonic forms that express property concepts conform to Dixon's cross-linguistic findings. This is demonstrated in Ameka (1991, Chapter 5) where it is argued that the AGE and PHYsical PROPERTY semantic type notions are expressed by basic verbs which convert to adjectives on the surface. HUMAN PROPENSITY concepts are expressed by nouns and SPEED by adverbs. All this is consistent with Dixon's findings. However, such a picture is incomplete and misleading because, ideophonic simple adjectives are associated with each of the seven semantic types as I demonstrate in the next section. The conclusion that would have to be drawn there is that Ewe has an open adjective class even at the deep level. 


\subsubsection{Ideophonic monomorphemic adjectives}

I assume that idcophones that express property concepts associated with the semantic types are basic and simple adjectives which convert to other parts-ofspeech without any overt modification. In Table 1, I give a sample of ideophonic adjectives and their semantic type association with an indication as to whether they can function in the same form as verbs and/or adverbs as well.

As is evident from the Table, there are ideophonic adjectives associated with each of the seven core semantic types. From this point of view, Ewe has an adjective class. Since many more items could be added especially to the ideophonic sub-class, it can be argued that the class is an open one. If this proposal is accepted then it could be said that Ewe has a large open class of underived or deep adjectives. However, if ideophones are ignored in the classification and treatment of adjectives, then the characterization would obviously be different. The implication for Ewe in that case is that it has a very small class of basic adjectives consisting of five items as noted above. This shows that the kind of data considered in the analysis affects the characterization of the adjective class in a language. Apart from these underived adjectives, however, Ewe also has a number of productive processes for forming words to express property concepts (see Ameka 1991, 1999). Taking the two classes of underived and derived adjectives together, it is clear that Ewe indeed has a large open adjective class whether à la Dixon or à la Lyons. Ideophones play a central role in this class.

One of the clear ways in which ideophones are central in the adjective class in Ewe is evidenced by the fact that ideophonic adjectives enter into systematic oppositions with non-ideophonic adjectives. Consider these pairs

\begin{tabular}{|c|c|c|c|}
\hline a. $f \hat{e}$ & 'young' & tsitsĭ & 'old' \\
\hline b. gbadzaa & 'flat, wide' & lúbuí & 'narrow' \\
\hline gbadzaa & 'flat, wide' & $x a ́ x x \xi$ & 'narrow' \\
\hline gbóbgó & ‘unripe’ & didì & 'ripe' \\
\hline blíbo & 'whole' & gbagbă & 'broken' \\
\hline múmù & 'raw' & dada & 'cooked' \\
\hline kpekpẽ & 'heavy' & wodzóé & 'light' \\
\hline
\end{tabular}

Observe that except for the last pair $(17 \mathrm{~g})$ all the others have an ideophonic form as the unmarked term in the pair. The term for 'flat/wide' has both an ideophonic and a non-ideophonic polar opposite (see $(17 \mathrm{~b}, \mathrm{c})$ ). The marked term for five out of the seven pairs are deverbal adjectival forms. In Dixon's terms these will be deeper basic verbs. Significantly two of the marked terms in the pairs are ideophonic adjectives (see 17b,g). This is not trivial because the patterning of antonymic oppositions with respect to basic category membership of the terms is one of the parameters in Dixon's typology. This is the feature that contributes to the characterization of a language as strongly adjectival or strongly verbal or neutral. For this characterization, 
Table 1. Multiple categorization potential of ideophonic adjectives

\begin{tabular}{|c|c|c|c|c|}
\hline & & adjective & verb & adverb \\
\hline \multicolumn{5}{|l|}{ AGE } \\
\hline$f \tilde{e}$ & 'young' & $\checkmark$ & $\checkmark$ & \\
\hline yéye & 'new' & $\checkmark$ & $\checkmark$ & $\checkmark$ \\
\hline kányá & 'early' & $\checkmark$ & & 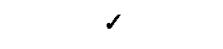 \\
\hline \multicolumn{5}{|l|}{ COLOR } \\
\hline yibos & 'black' & $\checkmark$ & $?$ & $\checkmark$ \\
\hline$(m u ́) m u(i)$ & 'green' & 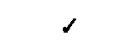 & $\checkmark$ & $\checkmark$ \\
\hline$k p i i$ & 'grayish' & $?$ & & $\checkmark$ \\
\hline \multicolumn{5}{|l|}{ DIMENSION } \\
\hline kpodzos & 'fat, thick' & $\checkmark$ & $\checkmark$ & $\checkmark$ \\
\hline bbos & 'long' & $\checkmark$ & $\checkmark$ & $\checkmark$ \\
\hline legbee & 'long' & $\checkmark$ & $\checkmark$ & $\checkmark$ \\
\hline lúbúi & 'narrow' & $\checkmark$ & & $\checkmark$ \\
\hline gbadzaa & 'flat/wide' & $\checkmark$ & & $\checkmark$ \\
\hline lekpelekpe & 'fat' & $\checkmark$ & & \\
\hline \multicolumn{5}{|l|}{ VALUE } \\
\hline bada & 'bad' & $\checkmark$ & $\checkmark$ & $\checkmark$ \\
\hline vávă & 'real' & $\checkmark$ & & $\checkmark$ \\
\hline yánáyăná & 'sweet' & $\checkmark$ & & $r$ \\
\hline \multicolumn{5}{|c|}{ PHYSICAL PROPERTY } \\
\hline blibo & 'whole' & $\checkmark$ & & $\checkmark$ \\
\hline gbsto & 'empty' & $\checkmark$ & & $\checkmark$ \\
\hline nyadrii & 'tough, hard' & 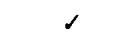 & $d$ & $\checkmark$ \\
\hline tsaklii & 'rough', & $\checkmark$ & $\checkmark$ & $\checkmark$ \\
\hline nogoo & 'round & $\checkmark$ & 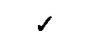 & 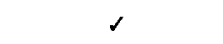 \\
\hline wódzóe: & 'light, not heavy' & $\checkmark$ & $\checkmark$ & $\checkmark$ \\
\hline múmǔ & 'raw/fresh' & $\checkmark$ & $\checkmark$ & $\checkmark$ \\
\hline \multicolumn{5}{|c|}{ HUMAN PROPENSITY } \\
\hline do & 'dull/slow/lazy' & $\checkmark$ & $\checkmark$ & (dododo 'slowly') \\
\hline dúdse & 'stupid/foolish & $\checkmark$ & $r$ & \\
\hline \multicolumn{5}{|l|}{ SPEED } \\
\hline kpata & 'sudden' & $s$ & & $\checkmark$ \\
\hline
\end{tabular}

Legend: $\quad \quad \quad=$ can function as $\ldots ; ?=$ marginally possible to function as $\ldots$ blank $=$ cannot function as

Dixon looks at the way the underived terms pattern in the antonymic oppositions involving actions ( raw vs. cooked) and non-action (e.g. sharp vs. blunt) oppositions. An examination of the oppositions manifested by the underived adjectives in Ewe (ideophones included) reveals the following: 


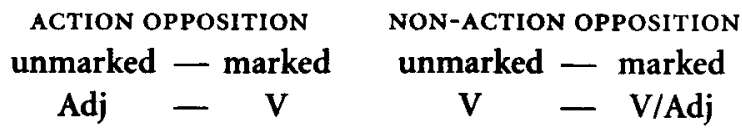

In terms of this parameter, Ewe is somewhere between strongly verbal to neutral languages. It manifests the kind of mixed syndrome described for Emai by Schaefer and Egbokhare (1993). The point to note here is that if ideophones were excluded from the analysis the picture will be different. Ewe in that case will come out as a strongly verbal language because the non-action oppositions will turn out to be expressed by verbs or deverbal adjectives which in Dixon's framework will be considered basic verbs.

Apart from the arguments presented so far there are other formal reasons for considering ideophonic adjectives as core members of the adjective class in Ewe. One of these is the fact that the conversion to other classes by zero conversion is not restricted to ideophones alone. Some deverbal forms can also function as adjectives or adverbs without any overt change in form as in (18).

\begin{tabular}{|c|c|c|c|c|c|}
\hline $\begin{array}{ll}\text { (18) } & \text { Verb } \\
& k \supset \\
& b \supset b s \\
& s \hat{e}\end{array}$ & $\begin{array}{l}\text { 'become clean' } \\
\text { 'become soft' } \\
\text { 'become strong' }\end{array}$ & $\begin{array}{l}\text { Adjective } \\
k \supset-k \supset-e \\
\text { bobo-e } \\
\text { sésíe }\end{array}$ & $\begin{array}{l}\text { 'holy' } \\
\text { 'soft' } \\
\text { 'strong' }\end{array}$ & $\begin{array}{l}\text { Adverb } \\
k \supset-k o-e \\
\text { bobo-e } \\
\text { sésíe }\end{array}$ & $\begin{array}{l}\text { 'holy' } \\
\text { ‘easy' } \\
\text { ‘strong' (dia- } \\
\text { lectal) }\end{array}$ \\
\hline
\end{tabular}

Similarly, there are some verbs which function as adjectives without any overt change in form just like the ideophonic words. In some dialects the adjectival forms carry a high tone suffix indicated in brackets in the examples below.

(19) Verb

vivi 'be(come) sweet'

lolo 'be(come) large, big'
Adjective

viví(i) 'sweet'

lolo $(\delta) \quad$ 'large, big'

From a diachronic perspective, it is possible that these verbs used to have a monosyllabic counterpart which has been lost. The current reduplicated verbal form could have been an intensive form and at that stage there could have been an adjectival form derived by reduplication from the CV verb (Ameka 1999). Synchronically, however, there is no $\mathrm{CV}$ form and there is homonymy between the adjectival and verbal forms.

Furthermore, like some derived adjectives (20a), some ideophonic adjectives $(20 \mathrm{~b}, \mathrm{c})$ also take the diminutive suffix, to signal expressive intensity:

\begin{tabular}{|c|c|c|}
\hline Verb & Adjective & Adjective+Dim \\
\hline a. fá 'become cold' & fáfá 'cold' & fafte 'pleasantly cool/cold' \\
\hline b. & yibos 'black' & yibSé 'nicely black' \\
\hline & tsralaa 'tall' & tsralé 'pleasantly tall' \\
\hline
\end{tabular}


Thus some of the formal properties of ideophonic adjectives are not necessarily unique to them but are features of members of the adjective class in Ewe. Hence any generalization about the class must take ideophones into consideration.

\section{Ideophonic adjectives and the domain of color}

One of the semantic types of property concepts à la Dixon is CoLor. It was shown in Section 4.2.1 that Ewe has two non-ideophonic underived color adjective terms namely, $y^{i} / y^{e}$ 'white' and $d z i / / d z \tilde{e}$ 'red'. The term for 'black' is an ideophone yibso. These terms are basic in the sense of Berlin and Kay (1969) because they are general - they apply to different classes of objects - as well as salient, i.e., they are readily elicitable, shared and used consistently by speakers. They do not refer to composite colors. Descriptors for other color concepts come from different sources such as circumlocutive descriptions, e.g. avu-mi-ksla literally, dog-shit-color, 'brown', or derived by metonymic associations, e.g. múmui 'green' related to múmu 'raw'; or from borrowing such as blû from English blue. It is thus fair to say that Ewe has a three basic color term. As such it is a Stage II language where the terms pattern as predicted by Berlin and Kay (1969) and Kay et al. (1997).

$\begin{array}{lll}y^{i} / y^{e} & \text { 'white' } & \text { (non-ideophonic) } \\ \text { yibso } & \text { 'black' } & \text { (ideophonic) }\end{array}$

$d z \tilde{l} / d z \tilde{e}^{\text {'red'(non-ideophonic) }}$

However, such a characterization is only possible if the ideophonic term is considered part of the basic color system. If the ideophone was excluded, then Ewe would be a two term language with an anomalous structure since both terms would be warm colors - white and red. Universally, in a two term language - a Stage I language there are two terms, one for white and one for black, or one for white plus warm colors, i.e., red and yellow and the other for black plus cool colors, i.e., green and blue.

Apart from this, native speakers' responses to the terms in a Word Association test ( 125 Ewe stimulus expressions) supports the view that the three terms are perceived to belong to the same domain and to be related. Some speakers gave the superordinate term amadédé 'color' for the three terms showing they are thought of as hyponyms to the same hyponym. Interestingly, yi/yé 'white' as stimulus triggered

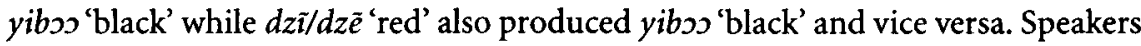
who responded in this way explained that the relation between the terms was one of an opposition or contrast either globally or with respect to specific domains such as the dye of cloth. It is significant that the two non-ideophonic warm color terms triggered the ideophonic cool color term as their complement. This shows that 
speakers view both types of words as belonging to the same system. The exclusion of the ideophonic terms would create an asymmetry in the system.

Similarly, if the ideophone yibos 'black' is excluded from the basic color terms of the language, there would be an incongruity between the color adjectives and the color verbs. In Ewe there are three color verbs which correspond to a three basic color system namely, fu 'become macro white', (n)yj 'become macro black' and biã 'become macro red'. The use of the word 'macro' in the glosses is meant to show that these verbs have general meanings and denote the macro field of the colors. Their meanings are made more specified by an adverbial term.
a. E-fu
yi-e
/ Yé-dé

3.sG-become_white white-ADV white-ADV

'It is (focal) white.'

b. E-fu

kpiii

3.sG-become_white gray IDEo

'It is gray / gray(ish) white.'

c. E-fu tititití

3.sG-become_white white IDEO

'It is immaculate white (like snow/cotton).'

(23)
a. É-biāa dzĩe //dzē-dé
3.SG-become_red red-ADV red-ADV
'It is (focal) red.'
b. É-biã hẽẽe
3.sG-become_red reddish IDEO
'It is rather red.'
c. E-biã gbánágbáná
3.sG-become_red red IDEO
'It is shining red.'
a. $E-y \bar{\partial}$
yiboo
3sG-become_black black
'It is (focal) black.'
b. E-ỹ kpékpékpé
3.sG-become_black deep black IDEO
'It is pitch black'

The discussion of the structuring of the color domain in Ewe thus shows that the incongruity that might be observed in the non-ideophonic basic part of the domain disappears once the ideophonic color term is brought into the picture as a complementary term in the system. This further shows that ideophones ought to be thought of as an integral part of the languages in which they occur, otherwise our account of and understanding of the nature of conceptual domains will be impoverished. 


\section{Conclusion}

In this paper, I have attempted to show that even though ideophones may deviate from the canonical phonological and morphological and morpho-syntactic properties of a language, they are part and parcel of the languages in which they occur. I have suggested that ideophones research would be free from the bottlenecks that hinder it at the moment if an attempt is made to discover correlations between clusters of properties of ideophones and language type. This can pave the way, in my view, for a better understanding of the phenomenon of ideophony in natural language. In short, what I am asserting is this: ideophones are an integral part of the languages in which they occur. It is time for linguists and linguistic anthropologists not only to describe them as a curiosity of these languages but to go further and include them in the data they consider in making typological generalizations about specific parts of the languages or of the languages as a whole. In this paper I have attempted to demonstrate the biased effect the neglect of ideophones may have on characterizing the nature and content of the adjective class in a language like Ewe.

\section{Notes}

* Parts of the material discussed here were presented at the International Symposium on Ideophones January 25-27, 1999 at St Augustin, Germany, and to the Language and Cognition Group of the Max Planck Institute of Psycholinguistics, Nijmegen. I am grateful to the participants at both meetings for their comments and encouragement. I am also grateful to Bill McGregor, David Wilkins, Melanie Wilkinson and Eva Schultze-Berndt for discussions I had with them on aspects of the topic.

1. Tom Güldemann (Ms.) reports that the form $t i$ in Shona (a cognate of the Zulu thi) is not only used among other things to introduce ideophones and ideophonic constructions in predicative use but also "ideophones can be attributed to a noun when the ti-clause is in the relative form." (p. 13).

2. The following abbreviations are used in the interlinear glosses:

$\begin{array}{llll}\text { ADI } & =\text { adjective } & \text { NPRES } & =\text { non-present, } \\ \text { ADV } & =\text { adverbializing suffix, } & \text { PL } & =\text { plural marker, } \\ \text { COP } & =\text { copula, } & \text { PRES } & =\text { present, } \\ \text { COMP } & =\text { complementizer, } & \text { PROG } & =\text { progressive, } \\ \text { DEF } & =\text { definiteness marker, } & \text { RED } & =\text { reduplicative, } \\ \text { DEM } & =\text { demonstrative, } & \text { REP } & =\text { repetitive, } \\ \text { DET } & =\text { determiner, } & \text { SG } & =\text { singular, } \\ \text { DIM } & =\text { diminutive, } & \mathbf{Q} & =\text { question marker, } \\ \text { ID } & =\text { prenominal identifier, } & \text { QT } & =\text { quantifier, } \\ \text { INDEF } & =\text { indefinite, } & 1 & =\text { first person, } \\ \text { INT } & =\text { intensifier, } & 2 & =\text { second person, } \\ \text { N } & =\text { nominal, } & 3 & =\text { third person. } \\ \text { NEG } & =\text { negative, } & & \end{array}$


High tones are marked throughout with an acute accent in addition to the low tones that are customarily marked in the traditional orthography with a grave accent. The hatchek marks a rising tone. Ewe orthographic $f$ and $v$ are the voiceless and voiced bilabial fricatives respectively which should be distinguished form ' $f$ ' and ' $v$ '. Unfortunately, the distinction between $f$ and $f$ is lost when the forms are represented in italic.

3. Cf. his statement that "From their function they must be classed as adverbs for they all describe the action of a verb; but most of them may be used as substantives or adjectives" (Westermann 1930: 187)

4. A common property of these underived adjectives is that they convert to a nominal by the prefixation of a low tone. The interesting thing is that the transparently derived adjective nyút 'good' illustrated above is the only derived adjective that behaves in similar fashion. This may be the language's response to the hole in the pattern of the simple adjectives. This is also an indication that the adjective class as such may be an emerging rather than a disappearing class. That is to say new members are added to the core in the course of history.

\section{References}

Ameka, F.K. 1986. "Have all the adjectives gone or are they emerging: Evidence from Ewe". Australian Linguistic Society 1986 Conference, The University of Adelaide, Adelaide.

Ameka, F. K. 1991. Ewe: Its Grammatical Constructions and Illocutionary Devices. PhD. Thesis, Canberra: Australian National University.

Ameka, F.K. 1992. "The meaning of phatic and connative interjections". Journal of Pragmatics 18(2/3):245-271.

Ameka, F. K. 1994. "Ewe". In C. Goddard and A. Wierzbicka (eds), Semantic and Lexical Universals: Theory and empirical findings, 57-86. Amsterdam: John Benjamins.

Ameka, F.K. 1999. "The typology and semantics of complex nominal duplication in Ewe". Anthropological Linguistics 41(1): 75-106.

Ansre, G. 1966. The Grammatical Units of Ewe. PhD. Thesis, London: University of London.

Amsre, G. 1988. "Towards the semantics of intensifiers in Ewe". 18th West African Languages Congress, Université de Niamey, 1988.

Awuku, A.S. 1992. The Nature of Picture Words in Anlo Ewe. MA. Thesis, Boulder: University of Colorado.

Berlin, B. and P. Kay. 1969. Basic Color Terms: Their universality and evolution. Berkeley: University of California Press.

Bot Ba Njock, H. M. 1977. "L'adjectif qualificatif dans trois langues bantu du Nord-Ouest: duala, basaa, bulu". In P. F. A. Kotey and H. Der-Houssikian (eds), Language and Linguistic Problems in Africa, 207-225. Columbia: Hornbean.

Breedveld, A. 1995. Form and Meaning in Fulfulde. Leiden: CNWS Research School of Asian, African and Amerindian Studies.

Childs, G. Tucker. 1994. "African ideophones". In L. Hinton et al. (eds), Sound Symbolism, 178-209. Cambridge: CUP.

Dakubu, M.E. Kropp. 1998. "Ideophones in Dangme and their place in linguistic semantics". Papers in Ghanaian Linguistics 11:1-18.

Dixon, R.M.W. 1982. Where have all the adjectives gone? And other essays on syntax and semantics. Berlin: Mouton. 
Thompson, S. 1988. "A discourse approach to the cross-linguistic category 'adjective". In J.A. Hawkins (ed.), Explaining LanguageUniversals, 167-185. New York: Basil Blackwell.

Welmers, W.E. 1973. African Language Structures. Berkeley: University of California Press.

Welmers, W.E. and B. Welmers. 1969. "Noun modifiers in Igbo". International Journal of American Linguistics 35: 315-322.

Westermann, D. 1927. "Laut, Ton und Sinn in westafikanischen Sudansprachen". In Festschrift Meinhof, 315-328. Hamburg: J.J. Augustin.

Westermann, D. 1930. A Study of the Ewe Language. Oxford: OUP.

Westermann, D. 1937. "Laut und Sinn in einigen westafrikanischen Sprachen". Archiv für vergleichende Phonetik 1:154-172; 193-212. 